\title{
Prevalence of dental caries in high school students in Asmara, Eritrea
}

Mussie Equbamichael MD, Tadessee Fissihaye, Amleset Hagos, Girmai Tsadu, Gide G/Egzabiher, Andat Kiflom.

Institutional Affiliation

Correspondence author:

\section{Abstract}

Background: Dental Caries is a common but unnoticed health problem affecting all age groups Dental Surgeon to population ration is 1:900000 rendering effective service with this scarce man power impossible.

Objective: To determine the prevalence of dental caries in Eritrea.

Method: A cross-sectional comparative study was conducted to determine the prevalence of dental caries and the factors contributing to it among high school students of Asmara. Data was collected in the month of April 2002. The study population was from 4 randomly selected schools out of the 13 high schools.

The data collection techniques were interviewing and observations using structured questionnaire and check list forms. The sampling method was multi stage 4 schools were selected by simple random sampling and systematic sampling was applied to select 100 students from each of the year sampled schools.

Results: Slightly more than $50 \%$ of the students had dental caries .Of these $123(67 \%)$ of the students had $1-3$ decayed teeth. The study did not reveal any significant association between the suspected contributing factors and dental caries. The awareness of the students in regard to their dental health status had significant association with the presence of dental caries. But 88 (55\%) of them did not seek medical care in spite of knowing that they had dental problem.

Conclusion: Dental carries are common among school going children. There is limited knowledge about the existence of the problem and even if present a substantial fraction does not seek medical attention. There is urgent need to institute national interventions to prevent the further increase in disease burden from dental diseases.

Conclusion: Dental caries are a major disease in Eritrea. IEC materials should be disseminated to curb further increase in dental problems targeting students at high schools as they are a vulnerable group.

\section{Introduction}

Disease of the teeth and adjacent oral structures are the most common maladies affecting human beings. Dental carries is a problem that has existed since prehistoric times and early historic times 1. It is a chronic disease affecting irreversibly the tooth.

The etiology of dental carries is an interaction of several factors, which determine whether an individual has much or little dental carries. The factors include bacteria of the oral cavities some of which are not pathogenic. But streptococcus mutans, lactobacillus, and actinomycosis are the virulent strains to cause dental caries 2 .

Within few minutes after cleaning teeth, a thin layer of salivary protein largely glycoprotein is deposited. This thin layer is called pellicles. Soon after the pellicles have been deposited bacteria populate it. Bacteria may be deposited directly on the enamel 3. The substrate factor, sugar is the principal contributing factor of dental caries. Several sugars can cause dental caries but sucrose causes the most damage for two reasons, it is the sugar most commonly eaten and it encourages the colonization and growth of dental plaque. When a soft civilized diet is used bacterial deposition is encouraged. The bacteria in the plaque are able to initiate an inflammation response. In the periodontal tissue host response is activated by bacteria which affect the enamel. The frequencies of consumption of refined carbohydrates in the length of time in the mouth are directly related to caries activities. In addition, it takes at least 24 hours and possibly longer for dental plaque to organize to the point when destructive activity can take place 4.

Many studies have shown that dental caries increases with age. A study done by Yayeh Yirad et. al reported that the dental caries prevalence rate in the age group of $15-19$ years was $49 \%$, compared to $65 \%$ in people aged 25 years and above 5 . Similarly, the study done by Gebreselassie et. al also shown a similar situation 3 .

It is important that preventive interventions for dental caries are carried out in young people before the problem has already developed. Since there is no published literature on the prevalence of dental caries in Eritrea, the objective of this study was to determine the factors contributing to dental caries among high school students of Asmara and to give appropriate recommendation for intervention.

\section{Methodology}

The type of study conducted was cross sectional comparative study on a population of 7944 high school students attending grades 8-10 classes.

The data collection technique used was observation (clinical examination) and interviewing using structured questionnaire. Some of the information collected was background, dietary habits, consumption of cariogenic foods and knowledge about dental caries.

The determined sample size was 400 calculated using degrees of precision $95 \%$ and margin of error $10 \%$. 
JOURNAL OF ERITREAN MEDICAL ASSOCIATION JEMA

The sampling method used was multistage. Out of 13 high schools in Asmara, four schools were selected by simple random sampling. Then sampling frame was prepared in each randomly selected school which was given a quota of 100 students. The sampling fraction and sampling interval was calculated for each school as shown below.

\begin{tabular}{|l|l|l|l|}
\hline Name of School & $\begin{array}{l}\text { Study } \\
\text { Population }\end{array}$ & $\begin{array}{l}\text { Sampling } \\
\text { interval }\end{array}$ & $\begin{array}{l}\text { Sampling } \\
\text { fraction }\end{array}$ \\
\hline Keih Bahri & 2299 & 22 & $1 / 22$ \\
\hline Li mAt & 1721 & 17 & $1 / 17$ \\
\hline Harnet & 1857 & 19 & $1 / 19$ \\
\hline Issak Teweldemedhin & 2076 & 21 & $1 / 21$ \\
\hline Total & 7953 & \multicolumn{3}{l}{} \\
\hline
\end{tabular}

To start selecting from each sampling frame, simple random sampling was used. After obtaining approval from the Ministry of Health, the investigators contacted the zonal education officer to get list of schools and the headmasters of the sampled schools were contacted later on. Data collection was started after training was given to research team members by an experienced dentist so that each member of the group has similar interpretation for the dental status of the respondents.

The data collected was finally entered into the computer and analyzed using Epilnfo version 6.2 program and appropriate statistical tests applied (chisquare test).

\section{Results}

A total of 400 students were studied of whom 225 (56.3 $\%)$ were males and 175 were females. The majority, 331 were Christians and 69 Moslems. The ethnic composition of the sample was 374 (93.5\%), Tigrigna in which 44 were Moslem (Geberti), 16 Tigre, 8 Saho, 1 Bilen, and 1 Hedareb.

Table 1. Distribution of sample by gender and education level.

\begin{tabular}{|l|l|l|l|l|l|l|}
\hline \multirow{2}{*}{ Grade } & \multicolumn{2}{|c|}{ Male } & \multicolumn{2}{c|}{ Female } & \multicolumn{2}{c|}{ Total } \\
\cline { 2 - 7 } & No & $\%$ & No & $\%$ & No & $\%$ \\
\hline 8 & 81 & 36.0 & 65 & 37.1 & 146 & 36.5 \\
\hline 9 & 96 & 42.7 & 67 & 38.3 & 163 & 40.7 \\
\hline 10 & 48 & 21.3 & 43 & 24.6 & 91 & 22.8 \\
\hline Total & 225 & 100 & 175 & 100 & 400 & 100 \\
\hline
\end{tabular}

The study comprises a total of 400 students out of which 146 (36.5\%) were grade 8, 163 (40.7\%) students grade 9 , and the rest were from grade 10 (22.8\%) and out of the total females, $37.1 \%$ are grade 8 students, $38.3 \%$ are grade 9 , and the rest grade 10 (Table 1 ).

More than $50 \%$ (207) of the students had dental caries. Those students who had decayed teeth, $67.6 \%$ of them had 1-3 decayed teeth, $25 \%$ with 4 to 6 decayed teeth and $2.2 \%$ had more than nine of their teeth decayed.

$52.6 \%$ of the female students had dental caries as compared to $49.3 \%$ as males. But there was no statistically significant difference. $(x 2=0.41, p$-value $>0.05$ )

Those students with good and fair knowledge about causes of caries were $41.8 \%$ and $50.8 \%$ respectively.

Almost two thirds of the students who had very good knowledge of cause of dental problems had no dental caries. But for those with no knowledge, only $33.3 \%$ had dental caries. There was no significant difference in the prevalence of caries between those who had little knowledge and those who had good knowledge $[(x 2=6.78, p$-value $>0.05)]$ (Table 2$)$.

Table 2. Knowledge about the cause of dental caries

\begin{tabular}{|l|l|l|l|}
\hline Level of knowledge & \multicolumn{4}{|l|}{ Dental caries } \\
\hline & Yes & No & Total \\
\hline Very Good & $6(40 \%)$ & $9(60 \%)$ & $15(100 \%)$ \\
\hline Good & $77(46.1 \%)$ & $90(53.9 \%)$ & $167(100 \%)$ \\
\hline Fair & $115(56.7 \%)$ & $88(43.3 \%)$ & $203(100 \%)$ \\
\hline No. knowledge & $5(33.3 \%)$ & $10(66.7 \%)$ & $15(100 \%)$ \\
\hline Total & 203 & 197 & 400 \\
\hline
\end{tabular}

NB: Very Good = reported or lack of care, food remnants

Good = reported lack of care or lack of care and sweet Food.

Fair $\quad=$ reported food remnants or sweet and food remnants.

No knowledge $=$ those who reported none of the above.

Among the 122(30.5\%) students who used good methods of cleaning $47.5 \%$ had dental caries, fair $50.8 \%$ and bad were $58 \%$.

Good:- means any one who used only tooth paste or tooth paste with any other method.

Fair:- means any one who used tooth stick or/and rinsing water.

Bad;- means any one who used rinsing only.

The students who used good method of cleaning, $47.5 \%$ had dental caries as compared to those who used fair method of cleaning habit, which was $50.8 \%$. As to the bad method of cleaning habit, almost $60 \%$ had dental caries. There was no significant difference between those who used good methods and bad methods $(x 2=0.72, p$-value $>0.05)$.

Of the $161(40.4 \%)$ of the students who had high frequency of cleaning, 84 (52.2\%) had dental caries, compared with 119 (50\%) with low frequency. The students with dental caries having scored high* and low** frequency of cleaning accounted for $52.2 \%$ and $49.8 \%$ respectively. Thus, the occurrence of dental caries seems not to be affected by the frequency of cleaning.

* High, means students who cleaned their teeth

twice or thrice per day

** Low, means students who cleaned their teeth daily or every other day or weekly.

With regard to the time of cleaning of the teeth, the majority of the respondents cleaned after each meal (45.3\%) and $16 \%$ did it each morning only and $14 \%$ cleaned after each meal and at bed time. And 61 ((15.3\%) cleaned their mouth when convenient. This could not be related to dental caries as there was no 
JOURNAL OF ERITREAN MEDICAL ASSOCIATION JEMA consistency with the timing and frequency of mouth cleaning in the data.

Among the 188 (47\%) students who reported low consumption of cariogenic food (51.6\%) had dental caries.

1. High, means students who consume cariogenic food staffs one or more per day

2. Low, means students who consume cariogenic one per week

Calorinogenic food staffs = biscuit, candy, cake, ice cream, chocolate and soft drinks.

Regular diet = Enjera, rice, pasta, bread.

The percentages of those students with dental caries, having high and low consumption of cariogenic food staffs were almost the same (1:1). The same was true for those with out dental caries.

$61.5 \%$ of the students who claimed to have tooth problems had dental caries as compared to $38.5 \%$ of the students who were not aware that they did have dental caries. There is statistical significance $(x 2=7.2$, $\mathrm{p}$-value $<0.05)$.

$55 \%$ of the students claimed to have tooth problem did not seek medical care.

Table 3. Types of treatment provided at home for dental problems.

\begin{tabular}{|l|l|l|}
\hline $\begin{array}{l}\text { Treatment used at } \\
\text { home }\end{array}$ & Number & Percent \\
\hline $\begin{array}{l}\text { Not used any form } \\
\text { of treatment }\end{array}$ & 43 & 48.9 \\
\hline Water with salt & 26 & 29.5 \\
\hline Anti pain & 7 & 8 \\
\hline Areki & 6 & 6.8 \\
\hline $\begin{array}{l}\text { Application of } \\
\text { herbs }\end{array}$ & 6 & 6.8 \\
\hline Total & 88 & 100 \\
\hline
\end{tabular}

Theabovetableshows that thetype of treatment sought at home for those students who reported to have tooth problem. Almost 49\% of the students in spite of having tooth problem did not take any measure to alleviate their aliment. Among those who did take something $57.8 \%$ of them used water with salt, anti pain, areki and application of herbs almost equal to it $14 \%$ each.

Table 4: Reasons for not visiting dental clinic when having tooth problem

\begin{tabular}{|l|l|l|}
\hline Reasons & Number & $\%$ \\
\hline 1. Long waiting time & 8 & 9 \\
\hline 2. Fear of unsafe procedure & 8 & 9 \\
\hline $\begin{array}{l}\text { 3. Unsuitable treatment } \\
\text { regiment }\end{array}$ & 2 & 2 \\
\hline 4. Affordability & 16 & 18 \\
\hline 5. Self treatment & 34 & 39 \\
\hline 6. "Negligence” & 20 & 23 \\
\hline Total & 88 & 100 \\
\hline
\end{tabular}

Self treatment and "negligence" were the main reasons given by those (62\%) who did not visit health facility (Table 4).

\section{Discussion}

The findings of the study showed that more than $50 \%$ of the students had dental caries with varying degrees of tooth decay. Although the prevalence rate was relatively high this trend has been reported in the region before. Yayeh Yirad et. al reported a prevalence rate of dental caries of $49 \%$ in students who were in the age group of 15-19 year 3. In our setting, the majority of those with the dental caries who had 1-3 teeth affected and about $7.5 \%$ had 7 or more teeth affected. This indicates that it is not only the prevalence of dental caries that was high but the severity of the disease was also high.

There was no difference in the prevalence between those students who had good knowledge and those with poor knowledge. This was a surprising which our study did not investigate. The observation is clear dislinkage between knowledge and practices. One can speculate contribution from socio-cultural factors and unaffordability of tooth cleaning ingredients.

Cleaning teeth was shown to prevent dental caries. Reports showed that toothpaste prevents dental caries 6. But this study did not confirm that the cleaning method (tooth paste) and for other habitual method of cleaning in both groups from who had dental caries and who did not differ. It was not clears why there was no difference between the two groups.

The frequency of teeth cleaning is also an important factor in preventing dental caries as plaque is formed in hours, which reduce the bacteria perforation. Here, the study did not show the difference between those who cleaned their teeth twice or thrice per day and the other group, but this could be explained by inconsistency of the students' response to the questions which address frequency and time of cleaning. Although in all texts it is a documented fact that cariogenic foods (easily fermentable) are the major factors in the pathogenesis of dental caries, this study failed to reveal the degree of their pathogenecity. However the reason for this weakness might be the consumption of cariogenic food should be explained in terms of frequency.

One of the findings that is observed in this study the awareness of the students regarding dental status $61 \%$ of the students who responded tooth problem and dental caries which is statistically significant, although they did not go to health facilities, they knew that they had problem, and $79 \%$ of those who said they did not have tooth problem, their dental status was healthy, but majority of the students did not seek medical care.

Despite saying that they had tooth problem $88(55 \%)$ of them did not visit health facility. Of these almost $50 \%$ of them did not take any measure and the measures taken by the rest 50\% were neither helpful nor acceptable. Although the study couldn't show tell to discover the reasons why the students did not seek medical care. This could be due to unacceptability and or inaccessibility of the health service. Other reasons for not seeking dental health service could be lack of awareness of the consequence of the illness and insidious nature of the disease. 


\section{JOURNAL OF ERITREAN MEDICAL ASSOCIATION JEMA}

\section{Conclusion}

Although the study has some limitations in regard to the structure of the questionnaire, the findings in this study had showed more than $50 \%$ of the students had dental caries.

On the other hand more than three quarters of the students who responded they had tooth problem had dental caries, but their health service seeking behavior was low, this could be due to inaccessibility and unacceptability which the study failed to discover clearly.

Ministry of education in collaboration with the Ministry of health should introduce and strengthen school health program. Health education curriculum should encompass dental hygiene. And Ministry of information in collaboration with the Ministry of health should disseminate relevant sustainable health information to increase public awareness in oral hygiene practice and encourage the public to modify dietary habits.

\section{Acknowledgement}

The group is grateful to Research and Human Resources Development of Ministry of

Health, to all facilitators in general and Dr.Yonathan Habtom, S/r Letezghi Afewerki and Ato Yohannes Haile in particular and special thanks also goes to Professor Asmerom Kidane and Professor A. Ngwengwe. At last but not least the group thanks to the Central Zone educational officer, the teachers and students.

\section{References}

1. A texst book of pathology structure and function in Diseases William Boyd 8th edition 19997 Lee Febigen pp 14291441

2. Davidson and Passmore Human Nutrition and Dieteries R. Passmole M.A Eastwood 8th edition pp 418-425

3. Prevalence of Dental carries in Sheshemane Woreda a thesis to partial Fulfillment to MPH Ghirmay Andemichael 1995 Addis Abbaba Ethiopia

4. Primary Prevention Dentistry 4th edition Normal O Harries Arden G Christian pp 39-127 Appleton of Lange

5. Drugs, Diseases and the peridentium Robert A Seymour Peter A Seymoun et al 1st ed.pp 14 Oxford University press

6. Eritrea health profile 2000 report R-HRD, MoH May 2001, Asmara-Eritrea.

7. Manual of oral health survey 4th edition, WHO 1997 Geneva.

8. Essential of dental surgery pathology. R.A Cowson, 2nd edition $J$ and A churcel

9. $\mathrm{MOH}$ Zoba Maekel Annual Report 1999

10. MOE Central zone Unpublished date SEMISH 1999 